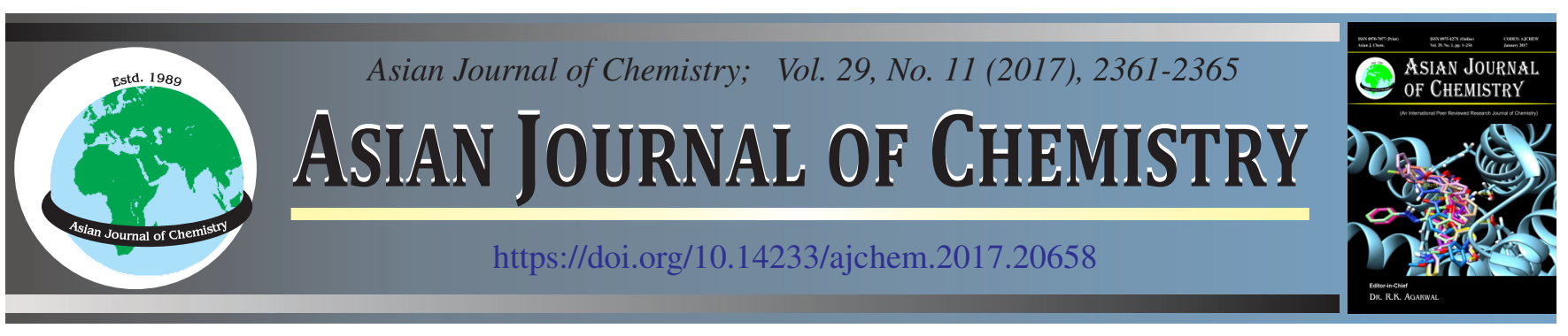

\title{
Synthesis and Characterization of Some Thiadiazole Compounds as New Corrosion Inhibitors for Mild Steel in Cooling Water
}

\author{
Ekhlas Qanber Jasim ${ }^{1}$, Munther Abduljaleel M.A. ${ }^{1, *}$ and RajaA Hussein Fayadh ${ }^{2}$
}

${ }^{1}$ Pharmaceutical Chemistry Department, College of Pharmacy, Basrah University, Basrah, Iraq

${ }^{2}$ Medical Technical Institute, Foundation of Technical Education, Basrah, Iraq

*Corresponding author: E-mail: muntheralamery @yahoo.com

\begin{abstract}
In present work, five 1,3,4-thiadiazole compounds were synthesized. The prepared compounds were identified by CHNS analysis, FT-IR and ${ }^{1} \mathrm{H}$ NMR spectroscopy. The corrosion rates in the presence of thiadiazole as a steel corrosion inhibitor in the cooling water system which taken from South Fertilizer Company, Basra, Iraq were measured by the weight loss method and potentiodynamic polarization measurements. The weight loss method was studied in different times (1-5 h) and in 303 to $333 \mathrm{~K}$ temperature range. Results obtained revealed that thiadiazole compounds performed as a corrosion inhibitor for mild steel in this medium and its efficiency attains to $86.55 \%$ at $5 \times 10^{-3} \mathrm{M}$ at $303 \mathrm{~K}$ and by potentiodynamic polarization measurements its efficiency attains to $85.35 \%$ in the same conditions. The apparent activation energies, enthalpies and entropies of the dissolution process and the free energies were determined and discussed.
\end{abstract}

Keywords: Mild steel, Corrosion, Thiadiazoles, Thermodynamics.

\section{INTRODUCTION}

Open recirculation cooling water systems are commonly used for industrial cooling purposes to efficiently dissipate unwanted process heat. The essence of cooling water system consists of plant heat exchange equipment and the water that passes through it to reduce heat from process fluids. Water is a universal solvent and thus becomes a potential medium to result into cooling water problems. It carries minerals, suspended colloidal and biological impurities [1].

The main problems associated with this system are scaling, corrosion, fouling and microbiological growth which if left untreated can lead to various problems like reduced operating efficiency, increased maintenance cost, loss in heat transfer efficiency and energy and ultimate shut down. Three basic types of corrosion, which occur in the cooling water system, are uniform, pitting and galvanic corrosion. The use of organic derivatives as inhibitors in the protection of metals and their alloys, cooling water corrosion is one of significantly important strategies $[2,3]$ due to the predominance in their chemical structures and properties, such as containing polar groups, conjugated double bonds or various heteroatoms-sulphur, nitrogen and oxygen [4,5]. For instance, benzotriazole (BTA) and its derivatives are often employed to protect copper and its alloys from corrosion. While owing to the toxicity of benzotriazole and its derivatives to environments [6,7], the extensive studies have been performed to look for new environmental friendly organic inhibitors in recent decades, including triazole derivatives [8], thiazolidin [9], oxadiazole derivatives [10], isoxazolidines [11,12], imidazole derivatives [13], etc.

The recent work includes synthesis and characterization of some thiadiazole derivatives, and used them as corrosion inhibitors in cooling water system of South Fertilizer Company, Basra, Iraq, using weight loss and galvanostatic polarization techniques. Moreover, the effect of temperature on the dissolution carbon steel, as well as, on the inhibition efficiency of the studied compounds was also investigated and some thermodynamic parameters were computed.

\section{EXPERIMENTAL}

Melting points were determined by open capillary and are uncorrected. The CHNS analysis measurements for the synthesized compounds were performed using EuroVector model EA3000A (Italy) and ${ }^{1} \mathrm{H}$ NMR spectra performed using Bruker model ultra shield $300 \mathrm{MHz}$ (Switzerland), at the analytical Laboratory of AL-ALBAYET University, Jordan. DMSO- $d_{6}$ was used as a solvent and TMS as an internal standard. IR spectra were recorded using KBr disc on Shimadzu FT-IR model 8400 Spectrophotometer at Chemistry Department, College of Education of Pure Sciences, Basrah University. 
Synthesis of thiadiazole 1 (1-phenyl-1,3,4-thiadiazole5-thiol) [14]: To a solution containing $95 \%$ ethanol and 0.1 mol of sodium hydroxide (dissolved in the least amount of water), $0.1 \mathrm{~mol}$ of thiobenzoic hydrazide was added, followed by $0.15 \mathrm{~mol}$ of carbon disulfide. The reaction mixture was heated under reflux for $3 \mathrm{~h}$ till all the evolution of hydrogen sulfide ceased. The resulting mixture was diluted with water and acidified with diluted hydrochloric acid containing ice. The reaction mixture was allowed to stand at the ice bath for $60 \mathrm{~min}$, filtered, washed with water and recrystallized from methanol (Scheme-I). The characterizations of the synthesized compounds are listed in Table-1.

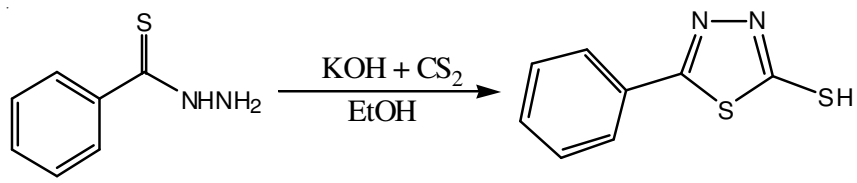

Scheme-I: Synthesis of thiadiazole

Preparation of thiadiazoles derivatives: The compounds, 5-ethylthio-1-phenyl-1,3,4-thiadiazole (2a), 5-butylthio-1phenyl-1,3,4-thiadiazole (2b), 5-pentylthio-1-phenyl-1,3,4thiadiazole (2c) and 5-benzylthio-1-phenyl-1,3,4-thiadiazole (2d), were prepared by the same method [15].

A mixture of $0.015 \mathrm{~mol}(2.67 \mathrm{~g})$ of compound $\mathbf{1}, 0.018$ mol of alkyl bromides or benzyl chloride and $0.02 \mathrm{~mol}(1.64 \mathrm{~g})$ of sodium acetate in $50 \mathrm{~mL}$ of ethanol was heated under reflux for $4 \mathrm{~h}$ and allowed to cool and poured into $100 \mathrm{~mL}$ of cold water containing ice. The solid product was collected and recrystallized from ethanol (Scheme-II). The characterizations of the products are summarized in Table- 1 .

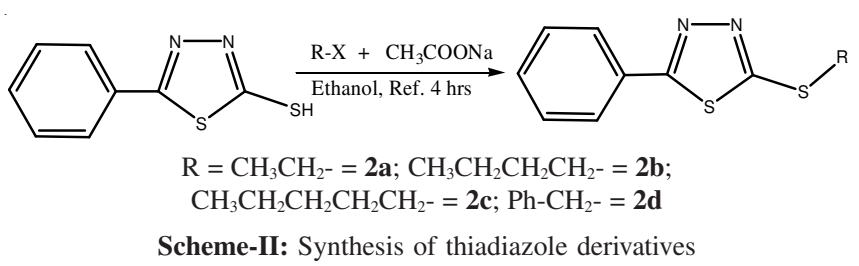

Weight loss measurements [16]: The mild steel sheets used in this present work have the composition presented in Table- 1 and strip of $3.5 \mathrm{~cm} \times 2.5 \mathrm{~cm} \times 0.4 \mathrm{~cm}$ size. Before measurements, the mild steel coupons were mechanically polished with series of emery paper of variable grades starting with the coarsest and proceeding in steps to the finest (600) grade, degreased with absolute ethanol, dipped into acetone and washed with deionized water. The coupons were dried and kept in desiccators. After weighing accurately, the specimens were immersed in $50 \mathrm{~mL}$ of cooling water and without and with addition of different concentrations of thiadiazole compounds inhibitor after different time (1-5 h), the strips were taken out washed, dried and weighed accurately. Duplicate experiments were performed in each and the mean value of the weight loss was reported. Inhibition efficiency E \%, surface coverage $(\theta)$ and corrosion rate were determined.

Tafel extrapolation method: Polarization studies were carried out using Bank Eleiktronkik Intellgent Controls Model MLab 200, Chemistry Department, Education College of pure Science, Basrah University, Iraq. Tafel polarization obtained by changing the electrode potential automatically from $(+250$ $\mathrm{mV}$ to $-250 \mathrm{mV}$ ) at open circuit potential with a scan rate 0.5 $\mathrm{mV} \mathrm{S}^{-1}$ to study the effect of inhibitor on mild steel corrosion [17]. The linear Tafel segment of cathodic and anodic curves were extrapolated to corrosion potential to obtain the corrosion current densities ( $\left.\mathrm{I}_{\text {corr }}\right)$.

\section{RESULTS AND DISCUSSION}

FT-IR spectra: FT-IR spectra of the synthesized compounds were carried out using $\mathrm{KBr}$ disc method. The IR data of the parent thiadiazole compound showed a band at $2766 \mathrm{~cm}^{-1}$ which is characteristic of the S-H stretching [18,19] (Fig. 1). This band was lacked in the S-substituted derivatives S-R (Table-2).

All IR spectra of thiadiazole compounds showed strongweak bands at $1623-1590$ and $1551-1487 \mathrm{~cm}^{-1}$, which are characteristic of the $\mathrm{C}=\mathrm{N}$ and $\mathrm{C}=\mathrm{C}$ ring stretching, respectively. Strong-medium bands at 1271-1245 and 1126-1032 $\mathrm{cm}^{-1}$ which are characteristic for $\mathrm{C}-\mathrm{N}$ stretching of thiadiazole ring [20]. Strong-weak absorption band at 3048-3024 and 784-746 $\mathrm{cm}^{-1}$, which are characteristic of aromatic C-H stretching and bending, respectively.

${ }^{1}$ H NMR: ${ }^{1} \mathrm{H}$ NMR spectra of the prepared thiadiazole compounds were performed in deuterated dimethyl sulfoxide solutions with tetramethylsaline as an internal standard. All these spectra showed signals at $2.5 \mathrm{ppm}$, which was due to DMSO solvent.

The parent thiadiazole (1) has a characteristic singlet signal at $2.821 \mathrm{ppm}$ due to proton of thiol group [19] and this signal is not appeared in the thiadiazole derivative compounds. The compounds 2a-d exhibited a characteristic aliphatic system which gave signals in the high field range between $0.912-4.528 \mathrm{ppm}$. All thiadiazole compounds exhibited multiplet signals in the downfield range between 7.272-8.168 ppm due to the protons of the aromatic systems (Table-3).

\section{Gravimetric measurements}

Inhibition efficiency at different times: Inhibition efficiency $(\mathrm{E} \%)$, surface coverage $(\theta)$ and corrosion rate was determined by using following equations [21]:

\begin{tabular}{|c|c|c|c|c|c|c|c|c|c|}
\hline \multirow{3}{*}{$\begin{array}{c}\text { Compd. } \\
\text { No. }\end{array}$} & \multicolumn{9}{|c|}{$\begin{array}{r}\text { TABLE-1 } \\
\text { PHYSICAL CHARACTERISTICS OF SYNTHES }\end{array}$} \\
\hline & \multirow{2}{*}{ m.f. } & \multirow{2}{*}{$\begin{array}{l}\text { m.w. } \\
(\mathrm{g} / \mathrm{mol})\end{array}$} & \multirow{2}{*}{ Colour } & \multirow{2}{*}{$\begin{array}{l}\text { m.p. } \\
\left({ }^{\circ} \mathrm{C}\right)\end{array}$} & \multirow{2}{*}{$\begin{array}{c}\text { Yield } \\
(\%)\end{array}$} & \multicolumn{4}{|c|}{ Elemental analysis (\%): Found (calcd.) } \\
\hline & & & & & & $\mathrm{C}$ & $\mathrm{H}$ & $\mathrm{N}$ & $\mathrm{S}$ \\
\hline 1 & $\mathrm{C}_{8} \mathrm{H}_{6} \mathrm{~N}_{2} \mathrm{~S}_{2}$ & 194.28 & White needle crystal & $209-211$ & 88 & $48.76(49.46)$ & $3.33(3.11)$ & $13.87(14.42)$ & $33.87(33.01)$ \\
\hline $2 \mathbf{a}$ & $\mathrm{C}_{10} \mathrm{H}_{10} \mathrm{~N}_{2} \mathrm{~S}_{2}$ & 222.33 & White needle crystal & $156-158$ & 74 & $54.42(54.02)$ & $4.69(4.53)$ & $13.02(12.60)$ & $28.26(28.84)$ \\
\hline $2 \mathbf{b}$ & $\mathrm{C}_{12} \mathrm{H}_{14} \mathrm{~N}_{2} \mathrm{~S}_{2}$ & 250.38 & White crystal & $147-149$ & 83 & $56.13(57.56)$ & $5.55(5.64)$ & $11.47(11.19)$ & $26.02(25.61)$ \\
\hline $2 c$ & $\mathrm{C}_{13} \mathrm{H}_{16} \mathrm{~N}_{2} \mathrm{~S}_{2}$ & 264.40 & White crystal & $140-142$ & 84 & $59.11(59.05)$ & $6.22(6.10)$ & $10.24(10.59)$ & $24.65(24.25)$ \\
\hline 2d & $\mathrm{C}_{15} \mathrm{H}_{12} \mathrm{~N}_{2} \mathrm{~S}_{2}$ & 284.39 & White needle crystal & $122-124$ & 80 & $63.10(63.35)$ & $4.34(4.25)$ & $10.02(9.85)$ & $22.19(22.55)$ \\
\hline
\end{tabular}


TABLE-2

KEY IR BAND OF SYNTHESIZED THIADIAZOLE COMPOUNDS

\begin{tabular}{|c|c|c|c|c|c|}
\hline 1 & $2 a$ & $2 \mathbf{b}$ & $2 c$ & $2 d$ & Assignment \\
\hline $3040 \mathrm{w}$ & $3040 \mathrm{w}$ & $3032 \mathrm{w}$ & $3048 \mathrm{w}$ & $3024 \mathrm{w}$ & $\mathrm{C}-\mathrm{H}$ stretching aromatic \\
\hline & $2924 \mathrm{~s}$ & $2927 \mathrm{~s}$ & $2945 \mathrm{~m}$ & $2940 s$ & C-H stretching aliphatic \\
\hline $2766 \mathrm{~m}$ & & & & & S-H stretching \\
\hline $1590 \mathrm{~m}$ & $1576 \mathrm{~s}$ & $1571 \mathrm{~m}$ & $1623 \mathrm{~s}$ & $1601 \mathrm{~m}$ & $\mathrm{C}=\mathrm{N}$ stretching of thiadiazole ring \\
\hline $1550 \mathrm{~m}, 1482 \mathrm{~s}$ & $1548 \mathrm{w}, 1487 \mathrm{~m}$ & $1487 \mathrm{~m}$ & $1551 \mathrm{~m}, 1478 \mathrm{~m}$ & $1481 \mathrm{~s}$ & $\mathrm{C}=\mathrm{C}$ stretching of aromatic rings \\
\hline $1464 \mathrm{w}$ & $1455 \mathrm{~m}$ & $1467 \mathrm{~m}$ & $1448 \mathrm{~m}$ & $1465 \mathrm{~m}$ & $\mathrm{~N}=\mathrm{N}$ stretching of thiadiazole ring \\
\hline & $1365 \mathrm{~s}$ & $1346 \mathrm{~s}$ & $1326 \mathrm{~m}$ & $1373 \mathrm{~m}$ & $\mathrm{C}-\mathrm{H}$ bending aliphatic \\
\hline $1267 \mathrm{~m}, 1032 \mathrm{~m}$ & $1267 \mathrm{~s}, 1064 \mathrm{~s}$ & $1271 \mathrm{~m}, 1089 \mathrm{~s}$ & $1245 \mathrm{~m}, 1126 \mathrm{~m}$ & $1242 \mathrm{~m}, 1112 \mathrm{~s}$ & $\mathrm{C}-\mathrm{N}$ stretching of thiadiazole ring \\
\hline $784 \mathrm{~m}$ & $766 \mathrm{~s}$ & $762 \mathrm{~s}$ & $768 \mathrm{~m}$ & $746 \mathrm{~s}$ & $\mathrm{C}-\mathrm{H}$ bending aromatic \\
\hline $677 \mathrm{~m}$ & $662 \mathrm{~m}$ & $678 \mathrm{~s}$ & $573 \mathrm{~m}$ & $597 \mathrm{~m}$ & C-S stretching \\
\hline
\end{tabular}

TABLE-3

${ }^{1} \mathrm{H}$ NMR DATA OF THIADIAZOLE COMPOUNDS

\begin{tabular}{|c|c|c|c|c|c|c|c|}
\hline \multirow{2}{*}{ Compd. No. } & \multicolumn{7}{|c|}{$\delta \mathrm{ppm}$} \\
\hline & Aromatic & $-\mathrm{SH}$ & $-\mathrm{CH}_{3}$ & $\mathrm{CH}_{3}-\mathrm{CH}_{2}-$ & $-\mathrm{CH}_{2}-\mathrm{CH}_{2}-\mathrm{S}-$ & $-\mathrm{CH}_{2}-\mathrm{CH}_{2}-\mathrm{CH}_{2}-\mathrm{S}-$ & $-\mathrm{CH}_{2}-\mathrm{S}-$ \\
\hline 1 & $7.265-8.254(\mathrm{~m}, 5 \mathrm{H})$ & $2.821(\mathrm{~s})$ & & & & & \\
\hline $2 \mathbf{a}$ & $7.425-7.921(\mathrm{~m}, 5 \mathrm{H})$ & & $1.416(t)$ & & & & $3.456(q)$ \\
\hline $2 b$ & $7.395-8.201(\mathrm{~m}, 5 \mathrm{H})$ & & $0.912(t)$ & $1.345(\mathrm{sx})$ & $1.684(q)$ & & $3.449(\mathrm{t})$ \\
\hline $2 c$ & $7.409-8.211(\mathrm{~m}, 5 \mathrm{H})$ & & $0.921(t)$ & $1.255(\mathrm{sx})$ & $1.371(\mathrm{p})$ & $1.816(\mathrm{p})$ & $3.441(t)$ \\
\hline 2d & $7.333-7.762(\mathrm{~m}, 10 \mathrm{H})$ & & & & & & $4.528(\mathrm{~s})$ \\
\hline
\end{tabular}

$$
\begin{gathered}
\mathrm{E}(\%)=\left(\frac{\mathrm{W}_{\text {corr }}-\mathrm{W}_{\text {corr (inh) }}}{\mathrm{W}_{\text {corr }}}\right) \times 100 \\
\theta=\frac{\mathrm{W}_{\text {corr }}-\mathrm{W}_{\text {corr (inh) }}}{\mathrm{W}_{\text {corr }}}
\end{gathered}
$$

where $\mathrm{W}_{\text {corr(inh) }}$ and $\mathrm{W}_{\text {corr }}$ are the weight loss values in the presence and in the absence of inhibitor, respectively.

$$
\mathrm{R}_{\text {corr }}=\frac{\Delta \mathrm{W} \times \mathrm{K}}{\mathrm{A} \times \mathrm{D} \times \mathrm{T}}
$$

where $\Delta \mathrm{W}=$ weight losses of metal $(\mathrm{g}), \mathrm{K}=$ constant $(5.34 \times$ $\left.10^{5}\right), \mathrm{A}=$ sample area $\left(\mathrm{cm}^{2}\right), \mathrm{D}=$ metal density $\left(\mathrm{g} / \mathrm{cm}^{3}\right)$ and $\mathrm{T}$ $=$ exposed time $(\mathrm{h})$.

The results of weight loss measurements show that by increasing the time the efficiency increases and there is good inhibition process for these thiadiazole compounds where the efficiency was in the range 80.12-86.55\% at the best time of $5 \mathrm{~h}$. There is proportional relationship between the inhibitor concentration and the efficiency. The best efficiency is recorded at the higher concentration of $10^{-3} \mathrm{M}$.

Kinetic parameters: In order to obtain the effect of inhibitors on the kinetic parameters, gravimetric weight loss experiments were conducted at $30,40,50$ and $60^{\circ} \mathrm{C}$ at $5 \mathrm{~h}$ of immersion in the absence and presence of thiadiazole at $5 \times 10^{-3} \mathrm{M}$. The activation parameters for the system were calculated (Table-4) from Arrhenius-type plot (4) and transition state eqn. 5 [22].

$$
\begin{gathered}
\log \left(\mathrm{R}_{\text {corr }}=\frac{-\mathrm{E}_{\text {act }}}{2.303 \mathrm{RT}}+\log \mathrm{A}\right. \\
\mathrm{R}_{\text {corr }}=\frac{\mathrm{RT}}{\mathrm{Nh}} \exp \left(\frac{\Delta \mathrm{S}}{\mathrm{R}}\right) \exp \left(-\frac{\Delta \mathrm{H}}{\mathrm{RT}}\right)
\end{gathered}
$$

Potentiodynamic polarization measurements: The inhibition efficiency was evaluated from the calculated $\mathrm{I}_{\text {corr }}$ values using the relationship [23]:

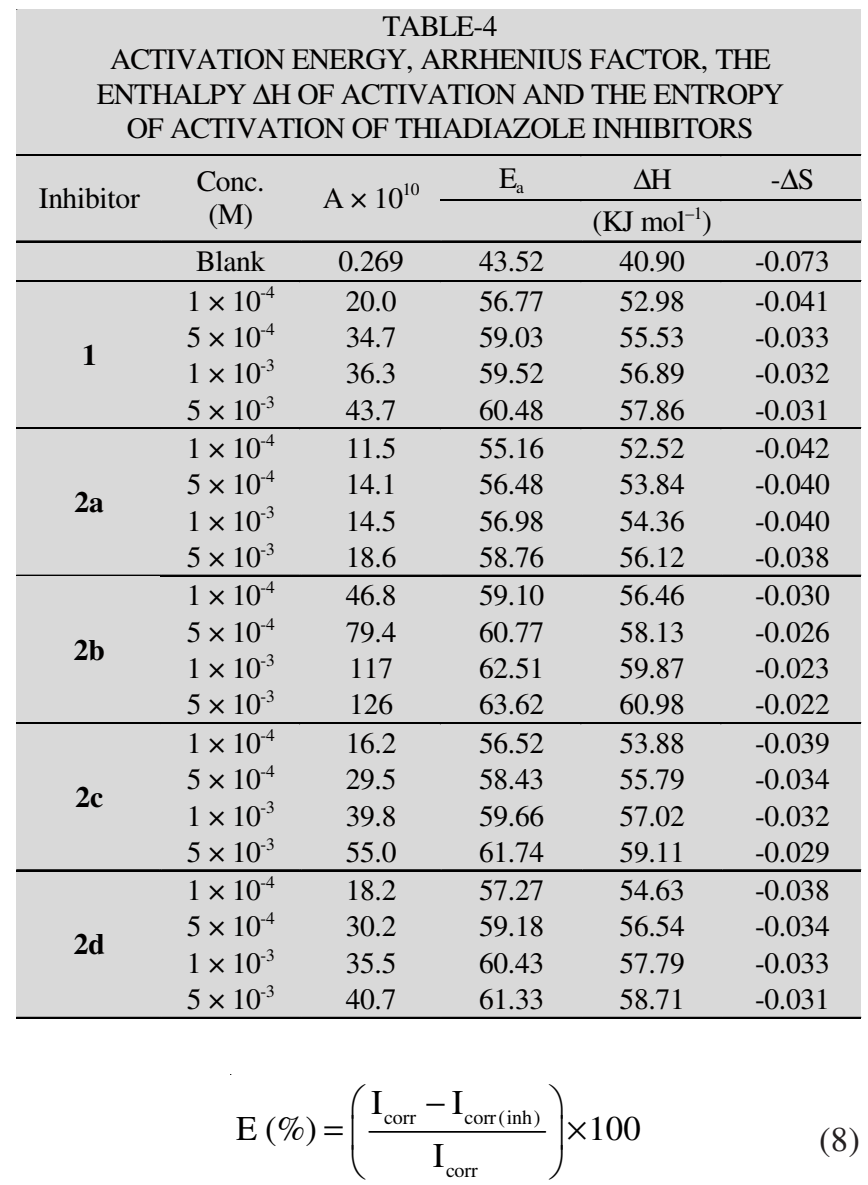

where $\mathrm{I}_{\text {corr }}$ and $\mathrm{I}_{\text {corr(inh) }}$ are the corrosion current in the absence and in the presence of inhibitor, respectively.

The polarization curves of thiadiazole compounds in cooling water at different temperature are represented in Fig. 1. It is clear that the inhibition decreases as the temperature increases. It is evident from the Tafel plots that the inhibitor adsorption shifted the corrosion potential $\left(\mathrm{E}_{\mathrm{corr}}\right)$ in the negative direction 

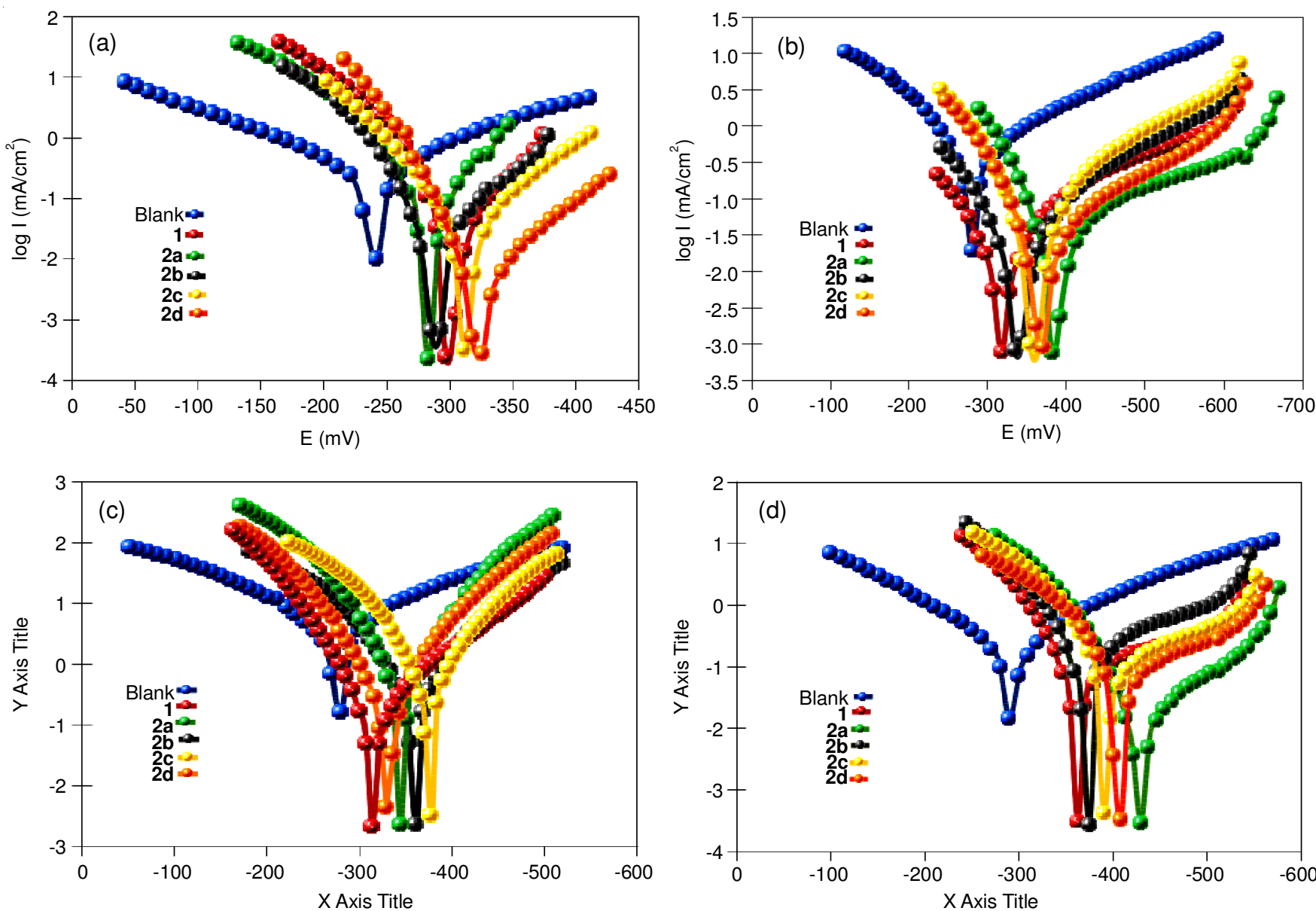

Fig. 1. Anodic and cathodic polarization curves (Tafel curves) of mild steel cooling water in the absence and presence of $5 \times 10^{-3} \mathrm{M}$ of inhibitors at different temperatures (a) $30{ }^{\circ} \mathrm{C}$, (b) $40{ }^{\circ} \mathrm{C}$, (c) $50{ }^{\circ} \mathrm{C}$ and (d) $60{ }^{\circ} \mathrm{C}$

TABLE-5

ELECTROCHEMICAL PARAMETERS FOR CORROSION OF MILD STEEL IN COOLING WATER IN THE PRESENCE OF DIFFERENT INHIBITORS AT VARIOUS TEMPERATURES

\begin{tabular}{|c|c|c|c|c|c|c|c|}
\hline Inhibitor & Temp. $\left({ }^{\circ} \mathrm{C}\right)$ & $\mathrm{I}_{\text {corr }}\left(\mu \mathrm{A} / \mathrm{cm}^{2}\right)$ & $\mathrm{E}_{\text {corr }}(\mathrm{mV})$ & $\beta C(\mathrm{mV} / \mathrm{dm})$ & $\beta a(m V / d m)$ & $\begin{array}{c}\text { E }(\%) \text { Elec. } \\
\text { method }\end{array}$ & $\begin{array}{l}\text { E \% Weight } \\
\text { loss method }\end{array}$ \\
\hline \multirow{4}{*}{ Blank } & 30 & 198 & -241.2 & -113.1 & 95.2 & - & - \\
\hline & 40 & 349 & -273.2 & -99.2 & 110.7 & - & - \\
\hline & 50 & 470 & -279.8 & -120 & 107.5 & - & - \\
\hline & 60 & 565 & -289.6 & -107.3 & 103.2 & - & - \\
\hline \multirow{4}{*}{1} & 30 & 40 & -294.2 & -120.8 & 95.5 & 79.79 & 80.12 \\
\hline & 40 & 79 & -307.8 & -155.1 & 108.3 & 77.36 & 76.38 \\
\hline & 50 & 132 & -314.1 & -142.1 & 88.2 & 71.91 & 70.27 \\
\hline & 60 & 199 & -384.5 & -143.5 & 88.9 & 64.77 & 63.83 \\
\hline \multirow{4}{*}{$2 \mathbf{a}$} & 30 & 33 & -290.4 & -133.1 & 96 & 83.33 & 83.04 \\
\hline & 40 & 63 & -340.4 & -191.6 & 83.5 & 81.94 & 80.06 \\
\hline & 50 & 108 & -365.9 & -194.7 & 80.9 & 77.02 & 77.61 \\
\hline & 60 & 162 & -424.4 & -134.8 & 81.6 & 71.32 & 70.02 \\
\hline \multirow{3}{*}{$2 \mathbf{b}$} & 30 & 34 & -291.3 & -143.3 & 101.8 & 82.82 & 84.80 \\
\hline & 40 & 76 & -329.1 & -178.5 & 91.5 & 78.22 & 76.69 \\
\hline & 60 & 185 & -394.2 & -161.9 & 75.7 & 67.25 & 68.57 \\
\hline \multirow{4}{*}{$2 c$} & 30 & 31 & -306.4 & -155.9 & 94 & 84.34 & - \\
\hline & 40 & 69 & -350.3 & -211.4 & 71.1 & 80.22 & - \\
\hline & 50 & 99 & -360.5 & -175.7 & 100.1 & 78.93 & - \\
\hline & 60 & 164 & -402.1 & -152.5 & 75.3 & 70.97 & - \\
\hline \multirow{4}{*}{$2 d$} & 30 & 29 & -312.3 & -116.5 & 124.8 & 85.35 & - \\
\hline & 40 & 61 & -320.4 & -161.8 & 85.4 & 82.52 & - \\
\hline & 50 & 101 & -354.4 & -185.7 & 94.3 & 78.51 & - \\
\hline & 60 & 147 & -414.1 & -117 & 79.1 & 73.98 & - \\
\hline
\end{tabular}


with reference to the blank, signifying that suppression of the cathodic reaction is the main effect of these corrosion inhibitors (Table-5).

Whereas, we found that by increasing the temperature, the current density increases, which led to decrease the corrosion efficiency. This may be attributed to decrease the adsorption process of inhibitor on the metal surface.

\section{Conclusion}

The corrosion behaviour of mild steel in cooling water in the absence and presence of thiadiazole compounds was investigated using weight loss and galvanostatic polarization techniques. From the results obtained the following conclusions could be drawn:

- Thiadiazoles exhibited good inhibition efficiency reaches to $86.55 \%$. The results showed that its inhibition efficiencies increased by increasing the concentration of inhibitors, but decreased with increase temperature.

- By increasing the side chain length of alkyl group, the inhibition efficiency was found to be increases.

- There are good agreements between weight loss and galvanostatic polarization techniques to determine the efficiency of corrosion inhibitor.

\section{REFERENCES}

1. M.M. Antonijevic, S.M. Milic and M.B. Petrovic, Corros. Sci., 51, 1228 (2009);

https://doi.org/10.1016/j.corsci.2009.03.026.

2. F.M. Al-Kharafi, B.G. Ateya and R.M.A. Allah, J. Appl. Electrochem., 34, 47 (2004);

https://doi.org/10.1023/B:JACH.0000005616.41240.d0.

3. M.M. Antonijevic, S.M. Milic, M.B. Radovanovic, M.B. Petrovic and A.T. Stamenkovic, Int. J. Electrochem. Sci., 4, 1719 (2009).

4. R. Ravichandran and N. Rajendran, Appl. Surf. Sci., 239, 182 (2005); https://doi.org/10.1016/j.apsusc.2004.05.145.

5. T. Murakawa, S. Nagaura and N. Hackerman, Corros. Sci., 7, 79 (1967); https://doi.org/10.1016/S0010-938X(67)80105-7.

6. X. Liu, X. Fang, Y. Tang, C. Sun and C. Yao, Mater. Sci. Appl., 2, 1268 (2011);

https://doi.org/10.4236/msa.2011.29171.
7. Z. Chen, L. Huang, G. Zhang, Y. Qiu and X. Guo, Corros. Sci., 65, 214 (2012); https://doi.org/10.1016/j.corsci.2012.08.019.

8. M. Mihit, S. El Issami, M. Bouklah, L. Bazzi, B. Hammouti, E.A. Addi, R. Salghi and S. Kertit, Appl. Surf. Sci., 252, 2389 (2006); https://doi.org/10.1016/i.apsusc.2005.04.009.

9. A. Doner, E.A. Sahin, G. Kardas and O. Serindag, Corros. Sci., 66, 278 (2013); https://doi.org/10.1016/j.corsci.2012.09.030.

10. M. Palomar-Pardavé, M. Romero-Romo, H. Herrera-Hernandez, M.A. Abreu-Quijano, N.V. Likhanova, J. Uruchurtu and J.M. Juárez-García, Corros. Sci., 54, 231 (2012);

https://doi.org/10.1016/j.corsci.2011.09.020.

11. S.A. Ali, M.T. Saeed and S.U. Rahman, Corros. Sci., 45, 253 (2003); https://doi.org/10.1016/S0010-938X(02)00099-9.

12. S.A. Ali, H.A. Al-Muallem, S.U. Rahman and M.T. Saeed, Corros. Sci., 50, 3070 (2008); https://doi.org/10.1016/j.corsci.2008.08.011

13. M.W. Jawich, G.A. Oweimreen and S.A. Ali, Corros. Sci., 65, 104 (2012); https://doi.org/10.1016/j.corsci.2012.08.001.

14. M.K. Bharty, A. Bharti, R.K. Dani, S.K. Kushawaha, R. Dulare and N.K. Singh, Polyhedron, 41, 52 (2012); https://doi.org/10.1016/j.poly.2012.04.025.

15. M.A. Mohammed Ali, Ph.D. Thesis, Basrah University, Basrah, Iraq (2008).

16. S. Banerjee, V. Srivastava and M.M. Singh, Corros. Sci., 59, 35 (2012); https://doi.org/10.1016/j.corsci.2012.02.009.

17. A.S. Abdul-Nabi and A.A. Hussain, J. Basrah Res. (Sci.), 38, 125 (2012).

18. A.E.-A. Gaber, M.S. El-Gaby, A.M. El-Dean, H.A. Eyada and A.S. AlKamali, J. Chin. Chem. Soc. (Taipei), 51, 1325 (2004); https://doi.org/10.1002/jccs.200400192.

19. R.M. Silverstein and F.X. Webster, Spectroscopic Identification of Organic Compounds, John Wiley \& Sons, New York, edn 6 (1998).

20. M.S. Khan, G. Chawla and M.A. Mueed, Indian J. Chem., 43B, 1302 (2004).

21. A. Singh, V.K. Singh and M.A. Quraishi, J. Mater. Environ. Sci., 1, 162 (2010).

22. A. Singh, V.K. Singh and M.A. Quraishi, Int. J. Corros., Article ID 275983 (2010); http://dx.doi.org/10.1155/2010/275983.

23. M.D. Shah, A.S. Patel, G.V. Mudaliar and N.K. Shah, Portug. Electrochem. Acta, 29, 101 (2011); https://doi.org/10.4152/pea.201102101. 